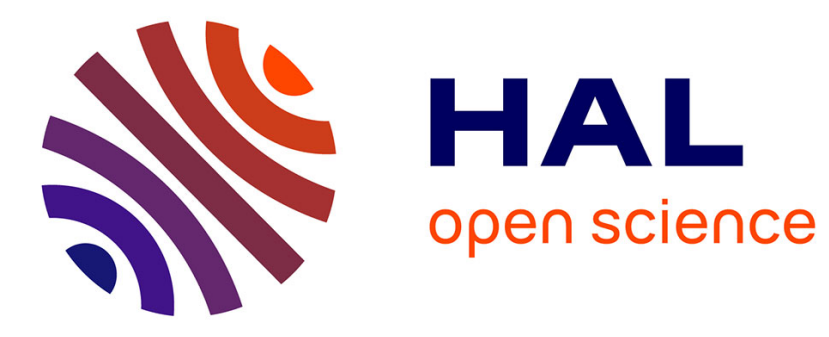

\title{
Boulder fall activity in the Jezero crater, Mars
}

Rishitosh K Sinha, A. Rani, S. Conway, S. Vijayan, A. Basu Sarbadhikari, M. Massé, N. Mangold, A. Bhardwaj

\section{To cite this version:}

Rishitosh K Sinha, A. Rani, S. Conway, S. Vijayan, A. Basu Sarbadhikari, et al.. Boulder fall activity in the Jezero crater, Mars. Geophysical Research Letters, 2020, 10.1029/2020GL090362 . hal-03008495

\section{HAL Id: hal-03008495 \\ https://hal.science/hal-03008495}

Submitted on 16 Nov 2020

HAL is a multi-disciplinary open access archive for the deposit and dissemination of scientific research documents, whether they are published or not. The documents may come from teaching and research institutions in France or abroad, or from public or private research centers.
L'archive ouverte pluridisciplinaire HAL, est destinée au dépôt et à la diffusion de documents scientifiques de niveau recherche, publiés ou non, émanant des établissements d'enseignement et de recherche français ou étrangers, des laboratoires publics ou privés. 


\section{Boulder fall activity in the Jezero crater, Mars}

2

3 R. K. Sinha1, A. Rani ${ }^{1}$, S. J. Conway ${ }^{2}$, S. Vijayan ${ }^{1}$, A. Basu Sarbadhikari ${ }^{1}$, M.Massé ${ }^{2}$, N. $4 \quad$ Mangold $^{2}$, A. Bhardwaj ${ }^{1}$

$5 \quad{ }^{1}$ Planetary Sciences Division, Physical Research Laboratory, Ahmedabad 380009, India.

$6{ }^{2}$ CNRS, UMR 6112 Laboratoire de Planétologie et Géodynamique, Université de Nantes, 7 Université d'Angers, France.

8

9

10

11

12

\section{Key Points:}

13
- We report on previously unrecognized boulder fall activity in Jezero crater - landing site of Mars 2020 Perseverance rover

- Hazardous boulders bigger (length $>2.7 \mathrm{~m}$ ) than the rover have recently fallen on the front of the western delta deposits within the crater

- Recently fallen boulders may have freshly exposed surfaces, which can be ideal targets for astrobiological investigations by the rover 


\section{Abstract}

26 Jezero crater is the landing site for the Mars 2020 Perseverance rover. We report 63 boulder fall

27 tracks within the crater using High Resolution Imaging Science Experiment (HiRISE) images. The

28 boulder tracks have both fresh and faded morphologies similar to those reported elsewhere on

29 Mars, but reported for the first time in Jezero crater. We combine observations from 16 boulder-

30 tracks on the western delta deposit with 47 in the surrounding regions to infer possible process(es)

31 of boulder destabilization, which can be tested with rover observations. This newly-found hazard

32 should be taken into account for rover operations. Boulders associated with tracks are geologically

33 "recent falls", so it is possible that the surfaces of these boulders may provide an opportunity to

34 sample material less exposed to radiation than other rocks at the martian surface and could be ideal

35 targets to analyze for organics.

Plain language summary

37 We have found tracks left by falling boulders within Jezero crater on Mars, which is the landing 38 site of the Mars 2020 Perseverance rover. The boulder tracks are observed on the slopes of the 39 delta deposits that the rover will explore, on the wall of Jezero crater and on the wall of a $\sim 2 \mathrm{~km}$ 40 diameter crater on the floor of Jezero crater. Boulders of a few meters in size have fallen down 41 moderately steep slopes, moving distances from a few tens of meters to nearly a kilometer. The 42 boulder tracks appear both fresh and degraded. The positions of the boulders and the appearance 43 of the tracks have not been observed to change, but the simple existence of the tracks suggests that 44 the boulder falls are recent and could be ongoing. Our results reveal a new location on Mars where 45 boulder fall activity is observed and indicate a new hazard to be taken into account by the rover 
47 be ideal candidates for obtaining samples that could be analyzed for signs of ancient life. Such

48 signs usually degrade rapidly with exposure to radiation.

\section{Introduction}

Boulder falls are energetic events and are known to occur on Mars (e.g. Roberts et al., 2012;

Brown and Roberts, 2019; Kumar et al., 2019). Hence, understanding if such a process could occur within the landing site of a roving mission on Mars is a key factor when planning operations to ensure the safety of the rover (e.g. Golombek and Rapp, 1997; Golombek et al., 2003, 2008, 2012). Recent boulder falls are characterized by a track marked in the regolith in the wake of the boulder. The tracks are continuous and/or discontinuous depressions of a similar width to that of the boulder with slightly raised edges and are produced by rolling, bouncing and rotation of the boulders (van der Bogert and Plescia, 2014). Over time, the boulder tracks may be erased by the deposition of dust (Beyer, 2012), infilling by aeolian deposits, and/or aeolian abrasion.

Isolated boulders are often key science targets for roving missions, as they are more easily accessible than outcrops and they can reveal information both on the mineralogy and geochemistry of the surface (e.g. Morris et al., 2000; Hamilton and Ruff, 2012; Squyres et al., 2006; Stolper et al., 2013; Pajola et al., 2017; Wiens et al., 2020). Boulders with tracks have the additional advantage that they can be traced back to the specific source region and hence enable a roving mission to sample rocks from the locations that would generally be difficult to reach (Schmitt and

\section{Cernan, 1973; Senthil Kumar et al., 2016).}

The landing site of the Mars 2020 Perseverance rover (Jezero crater; centered at $18.42^{\circ} \mathrm{N}, 77.67^{\circ}$

E) is a proposed paleolake with two inlet channels feeding the crater from the north and west (Figure 1a; Fassett and Head, 2005). The approximate position of the landing ellipse of the rover 
and the potential traversable routes of the rover to regions of interest within the landing site surrounds the partially eroded delta deposits (also known as western delta deposit) at the mouth of the western inlet channel (Figure 1b; Fassett and Head, 2005; Goudge et al., 2015, 2017; Farley, 2018; Mangold et al., 2020; Williams et al., 2020). Presence of aeolian landforms such as yardangs and transverse aeolian ridges (TARs) has been reported over the volcanic deposits on the front of the delta deposits (Chojnacki et al., 2018; Day and Dorn, 2019), and aeolian erosion has been suggested to have extensively eroded the delta deposits (Fassett and Head, 2005; Schon et al., 2012). In addition, the front of 50-60 m high western delta deposit hosts numerous boulders on its top surface, over its talus slope and at the base of the talus slope. Numerous boulders are found scattered across the wall of Jezero crater. If a boulder has detached from the face of the delta front or the crater wall in the very recent past at geological time scales, it is likely that the boulder would have produced a track as it rolled/bounced over the slope materials under the force of gravity. To our knowledge, boulder fall activity within Jezero crater has never been examined in detail. In this study we used 13 Mars Reconnaissance Orbiter (MRO) HiRISE images (0.25 or 0.5 m/pixel) and 4 HiRISE stereo-pair derived digital terrain models (DTM) (1 m grid spacing) (McEwen et al., 2007; Kirk et al., 2008) (Table S1 and S2, Figure S7) to search for boulder fall tracks, and analyze the morphology of identified boulder tracks. We examined all slopes for boulder tracks, including the flanks of delta deposits, Jezero crater wall, the walls of any other craters on the floor of Jezero, on the flanks of mounds adjacent to the Jezero crater wall, and on the flanks of any other topographic or hill-like features on the Jezero crater floor. To test whether boulder falls are currently active, we examined images with a long time separation (Table S3) to seek signs of change in the boulder position and the boulder track morphology (for example, fading of boulder tracks). We used the empirical shadow angle method (Lied, 1977; Evans and Hungr, 
92 1993) to analyze the runout distance of boulder falls on the delta deposits. Shadow angle is the

93 angle between the horizontal line from the talus apex and the line that connects the talus slope apex

94 with the most distant boulder fall (Duszynski et al., 2015). Please see the supporting information

95 for details on the data and methods. Finally, we discuss the possible process of boulder

96 destabilization and explore the potential scientific implications for the Mars 2020 Perseverance

97 rover.

\section{Results}

We have identified 63 boulder tracks within Jezero crater (Dataset S1). 16 boulder tracks are on the front of western delta deposits and the remaining 47 boulder tracks are in other regions of the

102 crater (43 boulder tracks on/near the wall of Jezero crater and 4 boulder tracks on the wall of a $\sim 2$

$103 \mathrm{~km}$ crater on the floor of Jezero crater) (Figure 1b-1d). We did not identify any convincing 104 changes in the position of the boulders and tracks have not faded over the $\sim 12$ years of available 105 images (Figure S1) (Table S3). We found that the tracks reported in this study do not 106 appear/disappear with respect to the change in the illumination conditions (such as incidence angle

107 and subsolar azimuth) (Table S1). 


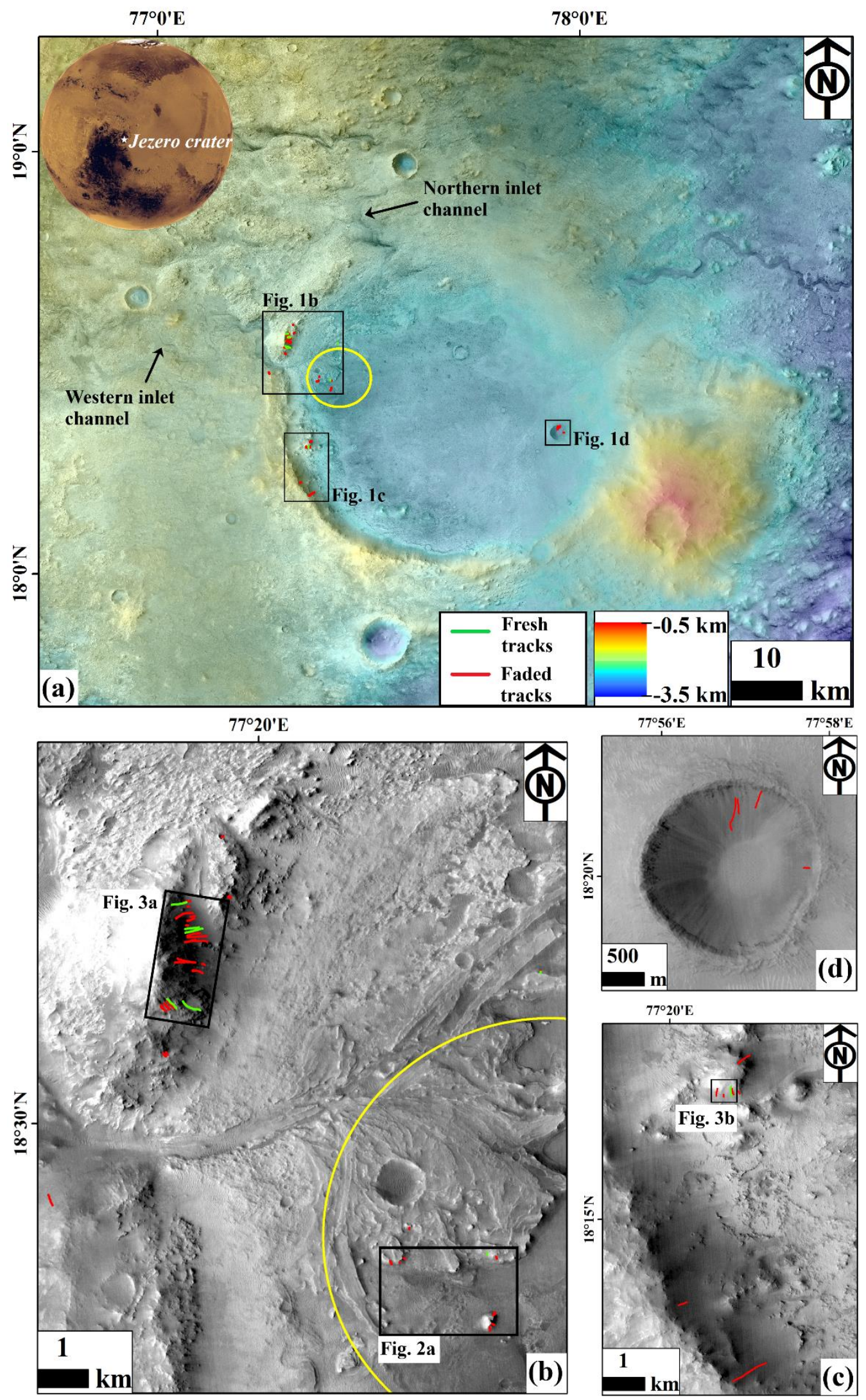


Figure 1. (a) Mars Orbiter Laser Altimeter (MOLA) and High Resolution Stereo Camera (HRSC) blend color elevation map over the Context (CTX) camera mosaic of the region around Jezero crater (Dickson et al., 2018). The location of Jezero crater (star) is shown on the global view of Mars (top-left) using Viking color imagery. The locations of panels b-d are shown by black boxes. The Mars 2020 Perseverance rover landing ellipse is in yellow. (b) Boulder fall tracks identified on the western delta deposits and western wall. (c) Additional boulder tracks identified on the western wall. (d) Boulder tracks identified on the wall of a $\sim 2 \mathrm{~km}$ crater on the floor of Jezero crater. Background is CTX mosaic in panels b-d. CTX image mosaic credits: NASA/JPL/MSSS/Caltech Bruce Murray Lab.

\subsection{Boulder falls on the western delta deposits}

We have identified 14 faded and 2 fresh boulder tracks on the front of western delta deposits

(Figures 1b, 2a). The morphology of faded boulder tracks varies widely between the tracks

(Figure 2b-d). For five of the faded boulder tracks, depressions are still identifiable, but for the 9 other faded boulder tracks only the track margin is discernible. We interpret this difference in boulder track morphology to be related to the extent to which they are mantled by dust, and therefore could give us an indication of the relative ages of the tracks. Fresh boulder tracks are characterized by distinct depressions (Figure 2e).

In general, all the boulder tracks end on the talus slope with an average length of $31 \mathrm{~m}$ (Figures 2b-c, 2e, 2g). The boulders associated with the tracks measure $<4 \mathrm{~m}$ in length (mean: $1.7 \mathrm{~m}$, standard deviation: $0.8 \mathrm{~m}$ ) (Figure 2f). Widths of boulder tracks vary from $1 \mathrm{~m}$ to $3.3 \mathrm{~m}$ (mean: $1.8 \mathrm{~m}$, standard deviation: $0.7 \mathrm{~m}$ ) (Figure 2f). The average slope between the start and end of the tracks ranged from $16^{\circ}$ to $29^{\circ}$ with most between $17^{\circ}$ and $24^{\circ}$ (mean: $22^{\circ}$, standard deviation: $3.8^{\circ}$ )

(Figure 2h). The longest observed boulder track $(67 \mathrm{~m})$ is associated with a big boulder (length: $3.7 \mathrm{~m}$ ) that has travelled beyond the base of talus slope, and the track superimposes aeolian landforms (e.g. TARs/dunes) (Figure 2d). Compared to the other fallen boulders around the delta 
140 deposits, this big boulder is double their average length $(1.7 \mathrm{~m})$. In comparison to the 63 boulder 141 falls reported in this study, this big boulder is nearly 3 times their average length (1.3 m). Both 142 longer (44 $\mathrm{m}$ to $67 \mathrm{~m})$ and shorter $(16 \mathrm{~m}$ to $30 \mathrm{~m}$ ) boulder tracks have an average slope between $14316^{\circ}$ and $21^{\circ}$. The average slope of the boulder source regions varies from $5^{\circ}$ to $47^{\circ}$ (mean: $23^{\circ}$, 144 standard deviation: $13.6^{\circ}$ ) (Figure 2h).

145

146

147

148

149

150

151

152

153

154

155

156

157

158

159

160

161

162 


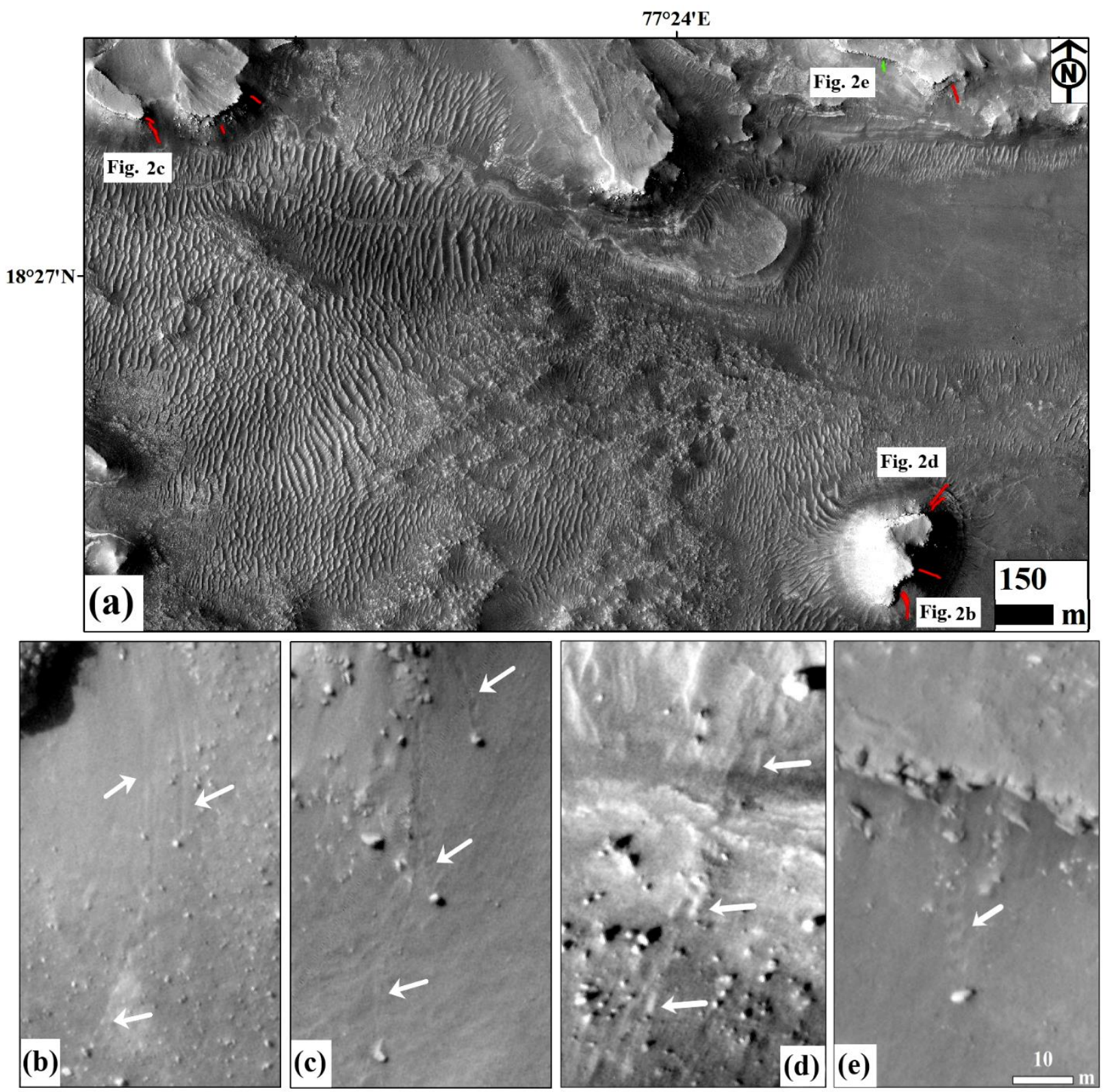

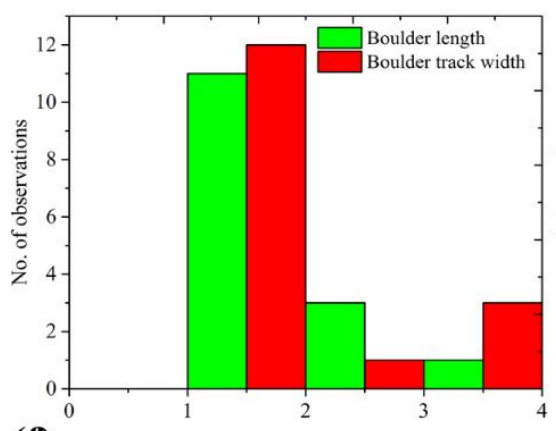

(f)

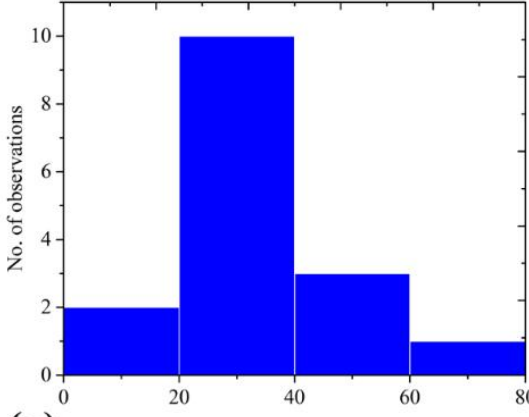

(g)

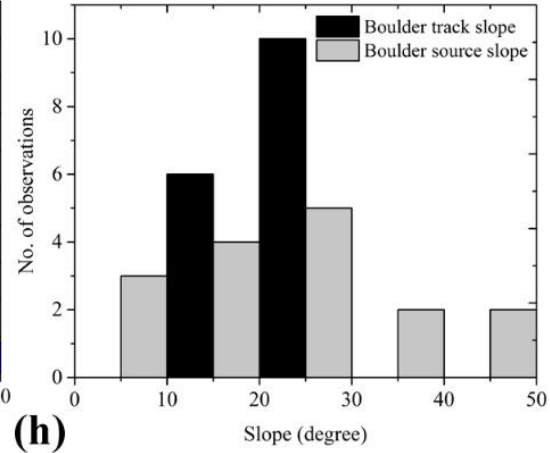


Figure 2. (a) Overview of the front of western delta deposits within Jezero crater on which fresh (green) and faded (red) boulder fall tracks are found. Locations of panels 2b-e are labeled. (b-d) Detailed view of faded boulder tracks (arrows). In Figure 2d, a custom stretch was applied to enhance contrast of the boulder track. (e) Detailed view of a fresh boulder track (arrow). Scale is same in panels b-e. HiRISE Image ID (a-e): PSP_002387_1985, credits: NASA/JPL/University of Arizona. (f-h) Morphometric characteristics of boulder fall on the front of western delta deposits. Histograms of (f) boulder length and boulder track width, (g) boulder track length, (h) boulder track slope and boulder source slope. The measured values plotted in $\mathrm{f}$-h are rounded to 1 decimal place.

\subsection{Boulder falls in the other regions of the crater}

40 boulder tracks out of the 47 observed tracks (Figures 1b-d and 3a-b; 36 tracks on/near the Jezero crater wall and 4 tracks on the wall of a $\sim 2 \mathrm{~km}$ crater on the Jezero crater floor) are classified as faded tracks (Figures 3f-g and 3i). The remaining 7 boulder tracks (on/near the Jezero crater wall) have a fresh morphology (Figures 3c-e and 3h). The faded tracks lack identifiable depressions, and appear infilled or mantled by dust, whereas the fresh tracks are characterized by distinct depressions. The boulders observed here (mean size: $1.2 \mathrm{~m}$, standard deviation: $0.6 \mathrm{~m}$ ) have formed tracks of length and width in the range $33 \mathrm{~m}$ - $900 \mathrm{~m}$ (mean: $190 \mathrm{~m}$, standard deviation: $155 \mathrm{~m}$ ) and $0.5-2.6 \mathrm{~m}$ (mean: $0.9 \mathrm{~m}$, standard deviation: $0.5 \mathrm{~m}$ ), respectively. The slope of the boulder source regions is slightly steeper (mean: $24^{\circ}$, standard deviation: $4^{\circ}$ ) than the slope of the boulder tracks (mean: $20^{\circ}$, standard deviation: $2.1^{\circ}$ ).

We find that the orientation of the slopes on which the boulder tracks are found are preferentially:

(1) southeast (Figure 3m), (2) east-southeast (Figure 3n), and (3) west-southwest/east-northeast (Figure 3o). 

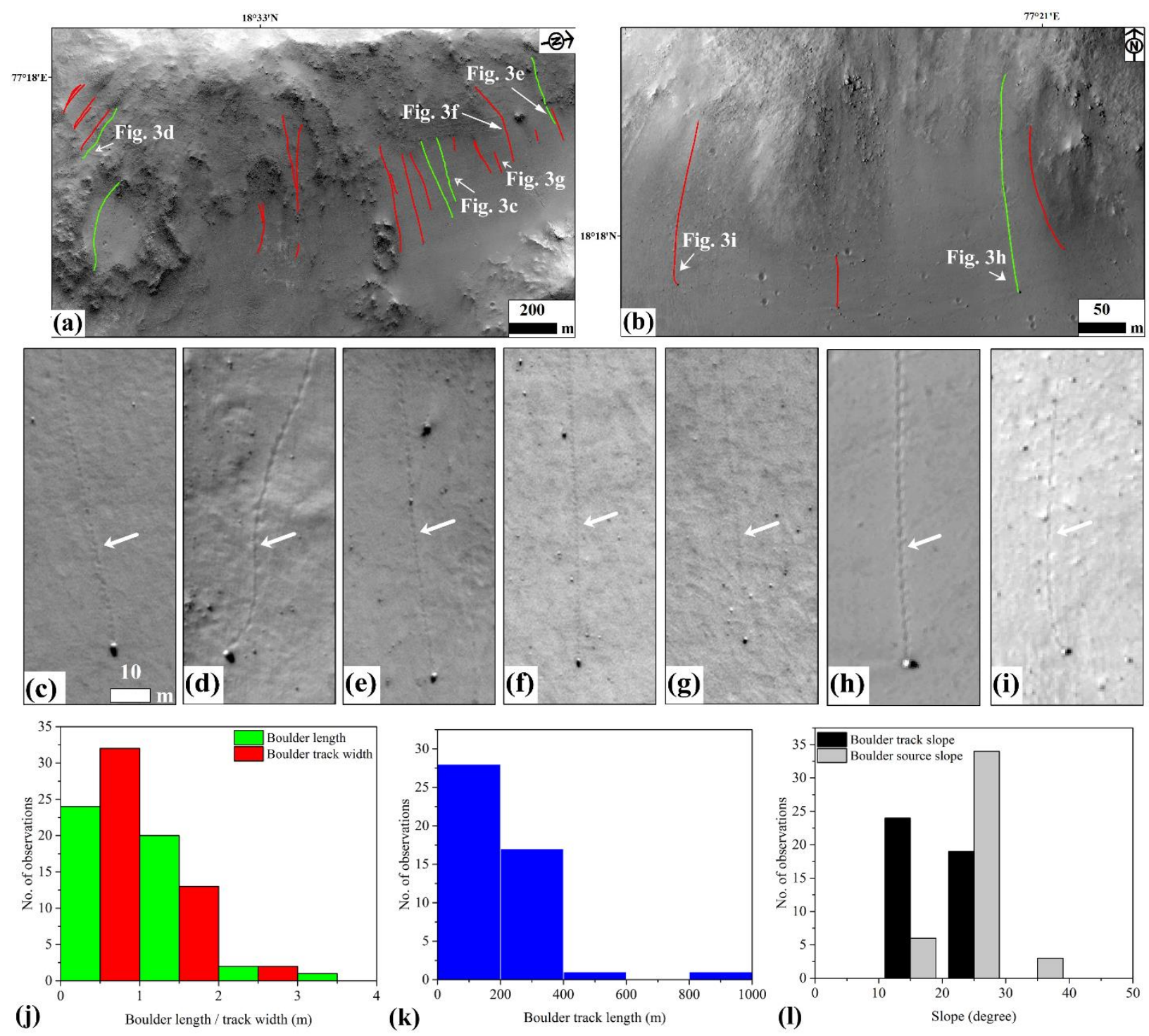

(m)

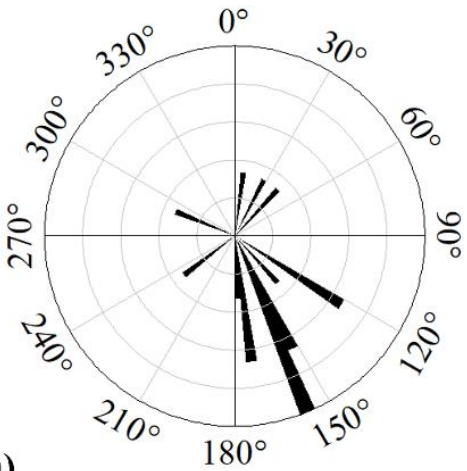

(n)
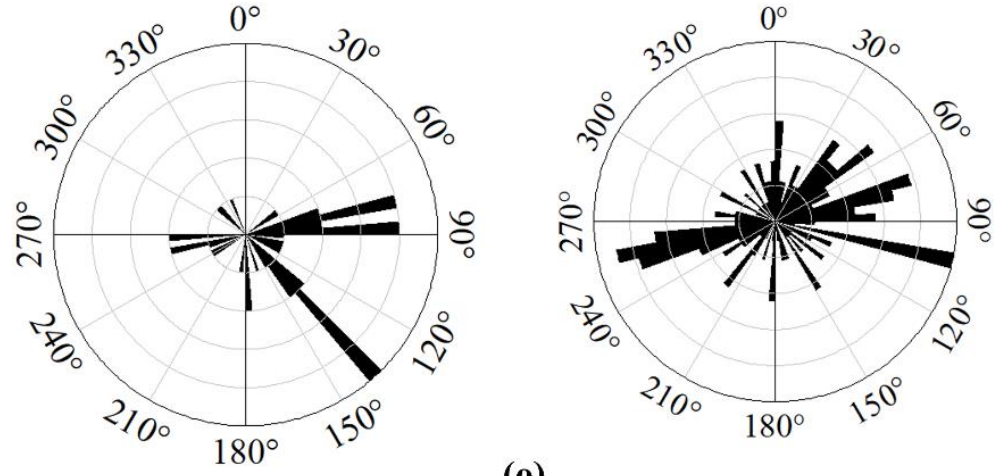

(o)

Figure 3. (a-b) Overview of the fresh (green) and faded (red) boulder tracks newly identified on/near the wall of Jezero crater. HiRISE Image ID (a): ESP_037119_1985. HiRISE Image ID (b): PSP_001820_1985. Locations of panels 4c-i are shown. (c-e): Detailed views of example 
faded boulder tracks (arrows). (f-i): Detailed views of example fresh boulder tracks (arrows). Scale is same in panels c-i. HiRISE Image credits: NASA/JPL/University of Arizona. (j-1) Morphometric characteristics of the boulder falls on/near the wall of Jezero crater. Histograms of (j) boulder length and boulder track width, (k) boulder track length, (1) boulder track slope and boulder source slope. The measured values plotted in $\mathrm{j}-1$ are rounded to 1 decimal place. Orientation of slopes on which the boulder fall tracks are observed on (m) delta deposits, (n) crater wall, and (o) the walls of 6 small craters (diameter: $\sim 1.5-5 \mathrm{~km}$ ) located within two to three crater radii of Jezero crater (Figure S2, S8).

\subsection{Boulder runout distance and shadow angle}

Runout characteristics of the boulders fallen around the delta deposits is inferred from the ratio between the horizontal distance travelled by the boulder $(\mathrm{L})$ and the vertical fall height $(\mathrm{H})$ of the boulder. The $\mathrm{L} / \mathrm{H}$ ratios for boulder falls on the delta deposits is greater than $\sim 1.6$ with a mean value of 2.5 (Figure 4a). The correlation coefficient for best-fit is 0.75 using a linear regression function. We find that on the delta deposits, both smaller $(\leq 1-1.2 \mathrm{~m})$ and bigger $(3.7 \mathrm{~m})$ boulders have $\mathrm{L} / \mathrm{H}$ ratio $\geq 3$, suggesting that boulder size is not the primary driver for runout distance on the delta deposits. The shadow angle is estimated as the arctangent of the relationship between the vertical drop of the boulder (elevation difference between the apex of talus slope and final elevation of the fallen boulder) and the horizontal distance travelled by the boulder (distance between the apex of the talus slope and final location of the fallen boulder). The shadow angle ranges between $16.2^{\circ}$ and $27.1^{\circ}$ for boulder falls on the delta deposits (Figure S3). On the front of delta deposits, the increase in runout distance $(67 \mathrm{~m})$ and reduction in minimum shadow angle $\left(16.2^{\circ}\right)$ resulted in boulder runout beyond the base of talus slope. This is consistent with the observational evidence that the runout of the boulders on the talus slope was not influenced by the aeolian landforms on the front of delta deposits. The mobility of the boulders that we have calculated (using the shadow angle) is within the range of those calculated for terrestrial rock falls (Evans and Hungr, 1993; Copons et al., 2009). Hence, there cannot be a significant acceleration 
219 (or addition of energy) above that of simply gravity acting alone. No trend is identifiable in the 220 plot of boulder fall size $\left(\mathrm{m}^{3}\right)$ versus tangent of the shadow angle (Figure 4c).
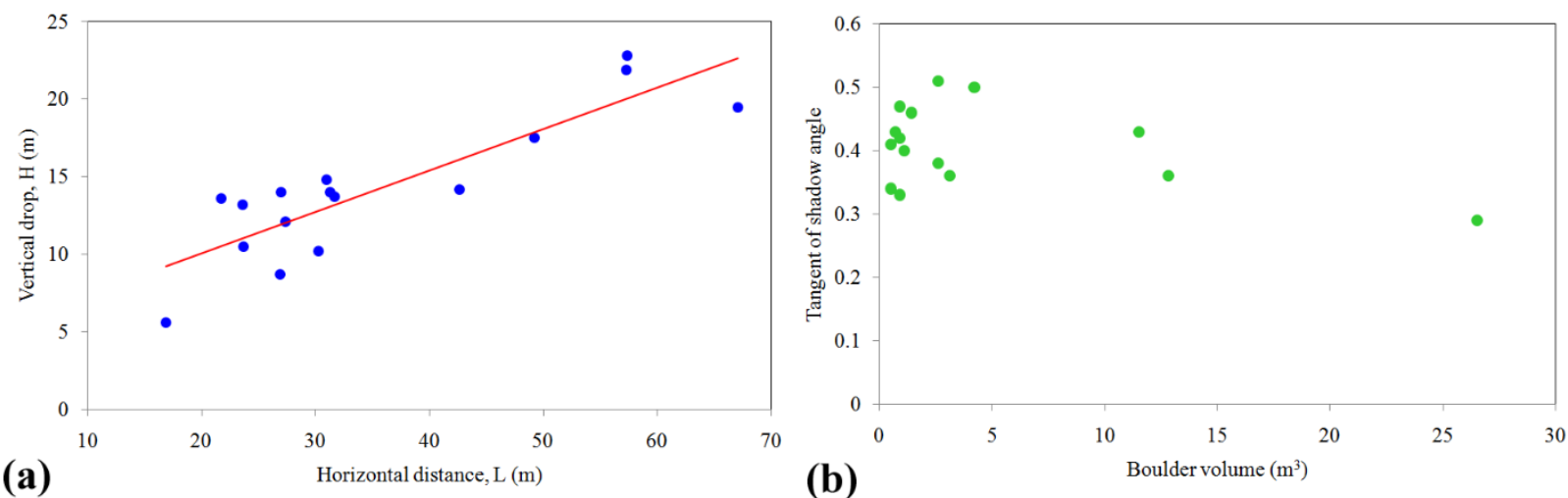

221

222

223

224

225

226

227

228

229

230

231

232

233

234

235

Figure 4. (a) Plot of horizontal distance (L) versus vertical drop (H) with fitted linear regression lines for delta deposits $\left(\mathrm{R}^{2}=0.75\right)$. (b) Plot of boulder volume (volume of individual boulders in $\mathrm{m}^{3}$ ) versus tangent of the shadow angle for boulders with tracks sourced at the delta deposits.

\section{Discussion}

We report previously undetected boulder fall activity at the landing site of Mars 2020 Perseverance rover. The average slopes $\left(22^{\circ}\right.$ for the delta front and $20^{\circ}$ for the other regions of the crater) onto which the boulders have fallen are lower than the angle of repose $\left(30^{\circ}\right)$ for dry particles on Mars (Kleinhans et al., 2011; Atwood-Stone and McEwen, 2013). Some (3 of the 16 boulders with tracks on the western delta deposits) of the boulders that have moved (length $>2.7 \mathrm{~m}$ ) are bigger than the Mars 2020 Perseverance rover (width $2.7 \mathrm{~m}$, and height $2.2 \mathrm{~m}$ ) (Figure S4). The proposed traverse of the Perseverance rover is along the front of delta deposits; therefore, it is important to understand the processes of boulder destabilization and whether it could still be ongoing today, which we will discuss further below.

\subsection{Process of boulder destabilization}


237 Evidence of frost has been reported at low latitudes on Mars (15-30 $)$ (Schorghofer and Edgett, 2006; Carozzo et al., 2009; Vincendon et al., 2010a, 2010b) and at the Opportunity rover landing site (at $1.95^{\circ} \mathrm{S}$ ) (Landis, 2007). If seasonal frosts also occur at Jezero crater, the rocks therein could be broken down by the stress produced due to volume change of frost condensed in cracks. Seasonal and diurnal temperature differences at latitudes poleward of $20-30^{\circ}$ are estimated to develop tensile stress >2-3 MPa in ice cemented ground (Mellon, 1997). However, whether thin frosts in fractured rocks at equatorial latitudes can induce such thermal contraction cracks is unknown but is a factor to consider for breaking down and destabilizing boulders in Jezero crater.

Solar insolation induced thermal stress has been proposed as a mechanism for rock breakdown on the surface of Mars (Eppes et al., 2015), and has been shown to lead to rock falls with preferential orientations (Tesson et al., 2020). However, we find that the boulder tracks do not exhibit any similarity in the preferred orientations (Figure 3m-o). So although thermal stresses probably contribute to rock breakdown, they do not seem to be the principal driver for destabilization.

Wind could scour beneath boulders causing them to fall (e.g., Malin and Edgett, 2001). Aeolian bedforms indicate modern easterly winds in the interior of Jezero crater (Chojnacki et al., 2018; Day and Dorn, 2019) and Jezero crater is located in a high sand flux region of Mars (Chojnacki et al., 2018). Previous studies have implicated aeolian erosion for the erosion of delta deposit within the crater (Fassett and Head, 2005; Schon et al., 2012; Day and Dorn, 2019) and a less erosion-resistant rock layer is known to be removed by aeolian scour and induce scarp retreat in Jezero crater (Williams et al., 2020). Hence, aeolian processes seem a likely driver for boulder destabilization in Jezero crater. 
258 Lithological differences can favor boulder destabilization. Mass wasting (in form of boulder falls

259 and movement of the boulders) of the sulfate-rich sediments in the equatorial region of Mars is 3-

2604 orders faster than the average erosion rate on the martian surface (Thomas et al., 2019).

261 Mineralogical mapping of the delta front where we have observed boulder falls indicates the

262 presence of Fe/Mg smectites (Goudge et al., 2017), but fresh boulder tracks are not confined to

263 this unit (Figure 1b), and various minerals have been reported in these regions (Goudge et al.,

264 2015, 2017). Hence, we do not find a specific role for lithology in explaining the boulder falls in

265 Jezero crater.

266 Boulders can be mobilized downslope by the ground shaking caused by meteorite impacts or

267 seismic shaking. We found no fresh impact craters within two to three crater radii of Jezero crater.

268 We found boulder fall tracks within Jezero crater as well as on the wall of 6 small craters 269 distributed within a radial distance of 60-70 km around the Jezero crater (two to three crater radii)

270 (Figure S2, S8). We have not observed any recent impact crater within this $60-70 \mathrm{~km}$ radius around

271 Jezero crater to account for impact causing shaking in the study region. Previous work has found

272 that boulder falls resulting from seismic shaking can be observed over a distance of several

273 kilometers from visible surface faulting (for example in Cerberus Fossae) (Roberts et al., 2012).

274 Jezero crater is close to a group of large, concentric grabens, called Nili Fossae, although there

275 have been no reports of these faults being active on geologically recent timescales. A detailed

276 examination of the HiRISE images of the Nili Fossae would be needed to understand if recent

277 mobilization of boulders has occurred systematically along the strike of the faults in the region,

278 which is beyond the scope of this paper. Hence, we maintain that seismic shaking is a plausible

279 hypothesis for boulder mobilization at this location, but have no corroborating evidence. A

280 previous study reported a paleomarsquake of moment magnitude ' $\mathrm{M}_{\mathrm{w}}$ ' up to 7.3-7.8 from boulder 
281 track data in Grjota Valles (Brown and Roberts, 2018), but InSight (Interior exploration using 282 Seismic Investigations, Geodesy and Heat Transport) instruments have only observed marsquakes, 283 ' $\mathrm{M}_{\mathrm{w}}$ ' $<4$ (Banerdt et al., 2020). Therefore, detailed modeling would be needed to understand the 284 proximity and magnitude of seismic events to mobilize boulders as large as $3.7 \mathrm{~m}$ at Jezero crater.

285 The data presented here are not sufficient to determine the recurrence interval of boulder falls at 286 Jezero crater; hence we cannot assess the likelihood of boulder falls happening during the Mars 2872020 mission. We have observed fresh and faded tracks in close proximity (Figures 1b-1d, 2, 3), 288 suggesting that neighboring tracks have different ages (as they should share similar environments), 289 and the processes destabilizing the boulders within Jezero crater has been active over a prolonged 290 period. The evidence of fresh tracks on the western delta deposits, on the western wall of crater, 291 and on the wall of small craters in the vicinity of Jezero crater suggests that the boulder 292 destabilization process is not local and was last active relatively recently. If the boulders continued 293 to move once the track has formed, then this motion has a magnitude less than a meter in $\sim 12$ 294 years.

\subsection{Other Implications for the Mars 2020 mission}

296 While the process for boulder destabilization is still unclear, the hypotheses we present could be 297 tested by the Mars 2020 Perseverance rover, scheduled to arrive in Jezero crater in early 2021. For 298 instance, the mast-mounted camera system (MastCam-Z) has wavelength filters that could detect 299 frost deposits (Rice et al., 2020), while the Radar Imager for Mars' subsurface eXperiment 300 (RIMFAX) would be able to identify any subsurface ice (Russell et al., 2020). The onboard 301 cameras can be used to monitor aeolian transport and abrasion and look for clues of thermal 302 breakdown. The role of wind or frost could also be tested by the Mars Environmental Dynamics 
Analyzer (MEDA), which will monitor wind speed and directions, surface temperature and measure local humidity (de la Torre Juárez et al., 2020).

Our observations open the door for in-situ analyses of boulders whose source areas would ordinarily not be accessible directly by the rover. The tracks allow their provenance to be better ascertained than boulders without tracks. Some of the boulders at the foot of the delta are present on slopes as low as $4-15^{\circ}$ (Figure S5), thus accessible by a rover, and have been detached from source regions where Fe/Mg smectites are thought to be present (Goudge et al., 2017). Boulders present on the foot of crater wall at slope as low as $20^{\circ}$ (Figures 1c, 3a-b and Figure S6) could 311 also provide access to the crater rim material, thus to ancient pieces of the crust (e.g. Goudge et 312 al., 2017). In addition boulders with tracks are geologically "recent falls", so these recently fallen 313 boulders may provide an opportunity to drill fresh exposures which might be less exposed to 314 radiation than other rocks at the martian surface and hence could present ideal targets to analyze 315 for organics (Cockell et al., 2016).

\section{Conclusions}

317 We demonstrate a previously unknown boulder fall activity on the talus slope of the western delta 318 deposits and on/near the wall of Jezero crater. The relative paucity of monitoring data (time step 319 of before-and-after images limited to $\sim 12$ years) does not allow us to conclude whether boulder 320 fall and boulder track modification are actively occurring at the present-day or not. Nevertheless, 321 our observations suggest boulders with visible tracks to have detached during recent geological 322 time scales. Surfaces of these recently fallen boulders therefore present a set of potential targets 323 for measurement of organic molecules by the Mars 2020 Perseverance rover. With the available 324 data we cannot determine which process or processes may have been responsible for the boulder 
325 falls in and around Jezero crater, but propose hypotheses that can be tested by the rover (such as:

326 thermal contraction, aeolian erosion, seismic shaking).

\section{Acknowledgements}

328 We thank the Editor (Andrew J. Dombard) and the reviewers (Mackenzie Day and Hirdy 329 Miyamoto) for providing us with constructive comments and suggestions. The work at the Physical 330 Research Laboratory is supported by the Indian Space Research Organisation, Department of 331 Space, Government of India. S. J. Conway, M. Massé, and N. Mangold are supported by the French 332 Space Agency, CNES. All the HiRISE image data used in this study are available via the PDS 333 node (http://ode.rsl.wustl.edu/mars/). All boulder track data relevant to the morphometric results 334 of this study are available in Data Set S1 (hosted at 335 https://doi.org/10.6084/m9.figshare.13083992.v1). We thank NASA/JPL/University of Arizona 336 for collecting and processing all the HiRISE images used in the study. Thanks to Jay Dickson and

337 the Caltech Bruce Murray Laboratory for Planetary Visualization (http://murray338 lab.caltech.edu/Mars2020/) for producing the global CTX mosaic and HiRISE digital elevation 339 models used in the study.

\section{References}

341 Atwood-Stone, C., \& McEwen, A. S. (2013). Avalanche slope angles in low-gravity environments 342 from active Martian sand dunes. Geophysical Research Letters, 40(12), 2929-2934.

343 Banerdt, W. B., Smrekar, S. E., Banfield, D., Giardini, D., Golombek, M., Johnson, C. L., 344 Lognonné, P., Spiga, A., Spohn, T., Perrin, C. and Stähler, S.C. (2020), Initial results from the 345 InSight mission on Mars. Nature Geoscience, 1-7. 
Brown, J. R., \& Roberts, G. P. (2019), Possible evidence for variation in magnitude for marsquakes from fallen boulder populations, Grjota Valles, Mars. Journal of Geophysical Research: Planets, 124(3), 801-822.

Carrozzo, F. G., Bellucci, G., Altieri, F., D’aversa, E., \&Bibring, J. P. (2009). Mapping of water 351 frost and ice at low latitudes on Mars. Icarus, 203(2), 406-420.

352 Chojnacki, M., Banks, M., \&Urso, A. (2018), Wind-driven erosion and exposure potential at Mars 2020 rover candidate-landing sites. Journal of Geophysical Research: Planets, 123(2), 468-488.

354 Cockell et al., Habitability: A review, Astrobiology, 16 (1), 89-117.

355 Copons, R., Vilaplana, J. M., \& Linares, R. (2009). Rockfall travel distance analysis by using 356 empirical models (Sola d'Andorra la Vella, Central Pyrenees). Natural Hazards \& Earth System 357 Sciences, 9(6). 359 cratering rate. Icarus, 225(1), 506-516.

360 Daubar, I. J., Banks, M. E., Schmerr, N. C., \&Golombek, M. P. (2019), Recently Formed Crater 361 Clusters on Mars. Journal of Geophysical Research: Planets, 124(4), 958-969.

364 de la Torre Juárez, M., Rodríguez Manfredi, J. A., Apéstigue, V., Arruego Rodríguez, I., Banfield, 365 D. J., Boland, J. S. Boland, P. G. Conrad, R. Ferrándiz, E.Fischer,M. Genzer, J.Gómez-Elvira. 
366 (2020). Performance of the MEDA Environmental and Meteorological Package for Mars 2020

367 After Integration. LPI, (2326), 2971.

368 Dickson, J. L., Kerber, L. A., Fassett, C. I., \&Ehlmann, B. L. (2018, March), A global, blended

369 CTX mosaic of Mars with vectorized seam mapping: a new mosaicking pipeline using principles 370 of non-destructive image editing. In Lunar and Planetary Science Conference (Vol. 49, pp. 1-2).

371 Dundar, M., Ehlmann, B. L., \&Leask, E. K. (2019), Machine-Learning-Driven New Geologic

372 Discoveries at Mars Rover Landing Sites: Jezero and NE Syrtis. arXiv preprint arXiv:1909.02387.

373 Duszyński, F., Migoń, P., \& Strzelecki, M. C. (2015). The origin of sandstone boulder aprons 374 along the escarpments of the Stołowe Mountains: are they all rockfall-derived? A new insight into 375 an old problem using the CONEFALL 1.0 software. Bulletin of Geography. Physical Geography 376 Series, 8(1), 19-32.

377 Eppes, M. C., Willis, A., Molaro, J., Abernathy, S., \& Zhou, B. (2015). Cracks in Martian boulders 378 exhibit preferred orientations that point to solar-induced thermal stress. Nature communications, $3796(1), 1-11$.

Evans, S. G., \&Hungr, O. (1993). The assessment of rockfall hazard at the base of talus slopes.

381 Canadian geotechnical journal, 30(4), 620-636.

382 Farley, K., Morgan, K.S., \&Williford, K. (2018), Jezero-Midway interellipse traverse mission 383 concept, Fourth Landing Site Selection Workshop for Mars 2020, October 18, 2018.

384 Fassett, C. I., \& Head III, J. W. (2005). Fluvial sedimentary deposits on Mars: Ancient deltas in a 385 crater lake in the Nili Fossae region. Geophysical Research Letters, 32(14). 
386 Golombek, M., \& Rapp, D. (1997). Size-frequency distributions of rocks on Mars and Earth analog 387 sites: Implications for future landed missions. Journal of Geophysical Research: Planets, 102(E2), $388 \quad 4117-4129$.

389 Golombek, M. P., Haldemann, A. F. C., Forsberg-Taylor, N. K., Dimaggio, E. N., Schroeder, R. 390 D., Jakosky, B. M., Mellon, M.T. and Matijevic, J.R. (2003). Rock size-frequency distributions on 391 Mars and implications for Mars Exploration Rover landing safety and operations. Journal of 392 Geophysical Research: Planets, 108(E12).

393 Golombek, M. P., Huertas, A., Marlow, J., McGrane, B., Klein, C., Martinez, M., M., Arvidson, 394 R.E., Heet, T., Barry, L., Seelos, K. and Adams, D. (2008). Size-frequency distributions of rocks 395 on the northern plains of Mars with special reference to Phoenix landing surfaces. Journal of 396 Geophysical Research: Planets, 113(E3).

397 Golombek, M., Huertas, A., Kipp, D., \&Calef, F. (2012). Detection and characterization of rocks 398 and rock size-frequency distributions at the final four Mars Science Laboratory landing sites. 399 IJMSE, 7, 1-22.

400 Goudge, T. A., Mustard, J. F., Head, J. W., Fassett, C. I., \& Wiseman, S. M. (2015). Assessing the 401 mineralogy of the watershed and fan deposits of the Jezero crater paleolake system, Mars. Journal 402 of Geophysical Research: Planets, 120(4), 775-808.

403 Goudge, T. A., Milliken, R. E., Head, J. W., Mustard, J. F., \&Fassett, C. I. (2017). 404 Sedimentological evidence for a deltaic origin of the western fan deposit in Jezero crater, Mars 405 and implications for future exploration. Earth and Planetary Science Letters, 458, 357-365. 
406 Goudge, T. A., Mohrig, D., Cardenas, B. T., Hughes, C. M., \&Fassett, C. I. (2018). Stratigraphy

407 and paleohydrology of delta channel deposits, Jezero crater, Mars. Icarus, 301, 58-75.

408 Gupta, S. \&Horgan, B. (2018), Mars 2020 Science Team Assessment of Jezero crater. In Mars 4092020 4th Landing Site Workshop, October 16-18, 2018.

410 Hamilton, V. E., \& Ruff, S. W. (2012). Distribution and characteristics of Adirondack-class basalt 411 as observed by Mini-TES in Gusev crater, Mars and its possible volcanic source. Icarus, 218(2), $412 \quad 917-949$.

413 Kleinhans, M. G., Markies, H., De Vet, S. J., \&Postema, F. N. (2011). Static and dynamic angles 414 of repose in loose granular materials under reduced gravity. Journal of Geophysical Research: 415 Planets, 116(E11).

416 Kneissl, T., van Gasselt, S., \&Neukum, G. (2011), Map-projection-independent crater size417 frequency determination in GIS environments-New software tool for ArcGIS. Planetary and 418 Space Science, 59(11-12), 1243-1254.

419 Kumar, P. S., Krishna, N., Lakshmi, K. P., Raghukanth, S. T. G., Dhabu, A., \&Platz, T. (2019), 420 Recent seismicity in Valles Marineris, Mars: Insights from young faults, landslides, boulder falls 421 and possible mud volcanoes. Earth and Planetary Science Letters, 505, 51-64.

422 Landis, G. A. (2007). Observation of frost at the equator of Mars by the Opportunity rover. LPI, 423 (1338), 2423.

424 Lied, K. (1977). Rockfall problems in Norway. ISMES Publication, 90, 51-53. 
425 Malin, M. C., \&Edgett, K. S. (2001), Mars global surveyor Mars orbiter camera: interplanetary 426 cruise through primary mission. Journal of Geophysical Research: Planets, 106(E10), 2342942723570.

428 Mangold, N., G. Dromart, V. Ansan, M. Massé, F. Salese, M. Kleinhans, 2020, Fluvial Regimes, 429 Age and Duration of Jezero Crater Paleolake and its Significance for the 2020 Rover Mission 430 Landing Site, Astrobiology, https://doi.org/10.1089/ast.2019.2132.

431 McEwen, A. S., Eliason, E. M., Bergstrom, J. W., Bridges, N. T., Hansen, C. J., Delamere, W. A., 432 Grant, J.A., Gulick, V.C., Herkenhoff, K.E., Keszthelyi, L. and Kirk, R.L. (2007), Mars 433 reconnaissance orbiter's high resolution imaging science experiment (HiRISE). Journal of 434 Geophysical Research: Planets, 112(E5).

435 Mellon, M. T. (1997). Small-scale polygonal features on Mars: Seasonal thermal contraction 436 cracks in permafrost. Journal of Geophysical Research: Planets, 102(E11), 25617-25628.

437 Morris, R. V., Golden, D. C., Bell III, J. F., Shelfer, T. D., Scheinost, A. C., Hinman, N. W., 438 Furniss, G., Mertzman, S.A., Bishop, J.L., Ming, D.W. and Allen, C.C. (2000). Mineralogy, 439 composition, and alteration of Mars Pathfinder rocks and soils: Evidence from multispectral, 440 elemental, and magnetic data on terrestrial analogue, SNC meteorite, and Pathfinder samples. 441 Journal of Geophysical Research: Planets, 105(E1), 1757-1817.

442 Pajola, M., Lucchetti, A., Fulle, M., Mottola, S., Hamm, M., Da Deppo, V., Penasa, L., Kovacs, 443 G., Massironi, M., Shi, X. and Tubiana, C. (2017), The pebbles/boulders size distributions on Sais: 444 Rosetta's final landing site on comet 67P/Churyumov-Gerasimenko. Monthly Notices of the 445 Royal Astronomical Society, 469(Suppl_2), S636-S645. 
446 Rice M. S., et al. The MastcamZ filter set and plans for multispectral imaging with Mars-2020 at

447 Jezero crater, 51th LPSC, Houston, 2020.

448 Russell, P. S., et al. RIMFAX ground penetrating radar field tests in the Western USA, 51th LPSC,

449 Houston, 2020.

450 Roberts, G. P., Matthews, B., Bristow, C., Guerrieri, L., \&Vetterlein, J. (2012), Possible evidence 451 of paleomarsquakes from fallen boulder populations, Cerberus Fossae, Mars. Journal of 452 Geophysical Research: Planets, 117(E2).

453 Schmitt, H. H., \&Cernan, E. A. (1973). A geological investigation of the Taurus-Littrow 454 Valley.[characteristics of Apollo 17 flight lunar landing site].

455 Schon, S. C., Head, J. W., \&Fassett, C. I. (2012). An overfilled lacustrine system and 456 progradational delta in Jezero crater, Mars: Implications for Noachian climate. Planetary and $457 \quad$ Space Science, 67(1), 28-45.

458 Schorghofer, N., \&Edgett, K. S. (2006). Seasonal surface frost at low latitudes on Mars. Icarus, $459 \quad 180(2), 321-334$.

460 Senthil Kumar, P., Sruthi, U., Krishna, N., Lakshmi, K. J. P., Menon, R., Gopala Krishna, B., 461 Kring, D.A., Head, J.W., Goswami, J.N. and Kiran Kumar, A.S. (2016), Recent shallow 462 moonquake and impact-triggered boulder falls on the Moon: New insights from the Schrödinger 463 basin. Journal of Geophysical Research: Planets, 121(2), 147-179.

464 Squyres, S. W., Arvidson, R. E., Bollen, D., Bell III, J. F., Brueckner, J., Cabrol, N. A., Calvin, 465 W.M., Carr, M.H., Christensen, P.R., Clark, B.C. and Crumpler, L. (2006). Overview of the 
opportunity mars exploration rover mission to meridianiplanum: Eagle crater to purgatory ripple. Journal of Geophysical Research: Planets, 111(E12).

Stolper, E. M., Baker, M. B., Newcombe, M. E., Schmidt, M. E., Treiman, A. H., Cousin, A., Dyar, M.D., Fisk, M.R., Gellert, R., King, P.L. and Leshin, L. (2013). The petrochemistry of Jake_M: A Martian mugearite. science, 341(6153).

Tesson, P. A., Conway, S. J., Mangold, N., Ciazela, J., Lewis, S. R., \&Mège, D. (2020), Evidence for thermal-stress-induced rockfalls on Mars impact crater slopes. Icarus, 113503.

Thomas, M. F., McEwen, A. S., \& Dundas, C. M. (2019), Present-day mass wasting in sulfaterich sediments in the equatorial regions of Mars. Icarus, 113566.

van der Bogert C.H., Plescia J.B. (2015), Boulder Track. In: Hargitai H., Kereszturi Á. (eds) Encyclopedia of Planetary Landforms. Springer, New York, NY.

Vincendon, M., Forget, F., \& Mustard, J. (2010a). Water ice at low to midlatitudes on Mars. Journal of Geophysical Research: Planets, 115(E10).

Vincendon, M., Mustard, J., Forget, F., Kreslavsky, M., Spiga, A., Murchie, S., \&Bibring, J. P. (2010). Near-tropical subsurface ice on Mars. Geophysical Research Letters, 37(1).

Wiens, R. C., Edgett, K. S., Stack, K. M., Dietrich, W. E., Bryk, A. B., Mangold, N., Bedford, C., Gasda, P., Fairen, A., Thompson, L. and Johnson, J. (2020). Origin and composition of three heterolithic boulder-and cobble-bearing deposits overlying the Murray and Stimson formations, Gale Crater, Mars. Icarus, 113897.

Williams, J., Day, M., Chojnacki, M., \& Rice, M. (2020). Scarp orientation in regions of active aeolian erosion on Mars. Icarus, 335, 113384. 